\title{
Shopping Malls, Platforms and Consumer Search *
}

\author{
Alexei Parakhonyak ${ }^{\dagger}$ and Maria Titova ${ }^{\ddagger}$
}

February 2018

\begin{abstract}
We consider a model of a market for differentiated goods in which firms are located in marketplaces e.g., shopping malls or platforms. There are search frictions between marketplaces, but not within. Marketplaces differ in size. We show that an equilibrium in which consumers start their search at the largest marketplace and continue in the descending order of size, always exists. Despite charging lower prices, firms in larger marketplaces earn higher profits. Under free entry, all firms cluster in one marketplace provided that search frictions are large enough. If a marketplace determines the price of entry, then the equilibrium marketplace size is a single-peaked function of search costs and is decreasing for most of the search cost range.
\end{abstract}

\section{JEL-codes: D43, D83, L13}

\section{Key Words: Shopping Malls, Consumer Search, Platforms}

${ }^{*}$ We thank Mark Armstrong, Maarten Janssen, David Ronayne, Anton Sobolev, participants of 7th Workshop on Consumer Search and Switching Costs, UCSD Workshop in Microeconomic Theory, Royal Economic Society 2017 and EARIE 2017 conferences, the editor and two anonymous referees for useful comments.

${ }^{\dagger}$ Department of Economics and Lincoln College, University of Oxford. E-mail: parakhonyak@yandex.ru.

${ }_{\ddagger}^{\ddagger}$ Department of Economics, University of California, San Diego. E-mail: mtitova@ucsd.edu. 


\section{Introduction}

In this paper we study markets for differentiated goods in which firms sell their products in various marketplaces: shopping malls, online platforms, etc. Quite often sellers of similar products tend to concentrate in one location. For example, souvenir sellers in Oxford are mainly located on High Street. Several large fabric retailers in Moscow are located on

Leninsky Prospect. Restaurants tend to cluster in a few streets in city centers or in "food courts" in airports, shopping centers and wholesale clubs. In online markets, more and more retailers tend to join large selling platforms, like eBay or Amazon. Apparently, the losses from tougher competition are more than outweighed by the fact that these large marketplaces are the starting point of consumers' searches.

We consider a general industry structure with an arbitrary number of marketplaces of arbitrary sizes. We assume that there is a positive cost for searching between the marketplaces and no search cost within each marketplace, although our results hold if search costs within each marketplace are identical and sufficiently low. Consumer search in our paper is directed by the size of each marketplace. Consumers prefer to visit larger marketplaces first. There are three forces contributing towards this decision. Firstly, large malls offer a greater variety of products, thus providing a better expected match between a consumer and a product. Secondly, a large concentration of firms under the same roof leads to strong competition and lower prices, making larger marketplaces even more attractive. Finally, there is a self-fulfilling component: as consumers expect lower prices in larger malls, they visit them first, and as a result the demand at larger marketplaces is more elastic, which reinforces lower prices. After consumers have visited all the marketplaces of a certain size, they either move to smaller places, or buy from a previously visited retailer. The feature that consumers may return to a previously visited firm before examining all options, which does not arise in random search models, is typical of the kind of directed search protocol we have in our paper.

We also study the incentives of firms to cluster in the same location e.g., a large shopping mall. If entry is free, our work shows that all firms prefer to concentrate at the 
same location when search costs are large and remain as stand-alone stores when search costs are small. The range of search costs for which firms prefer to be stand-alone is small and shrinks fast as either the size of the main marketplace, or the periphery, increases. If the mall is allowed to choose its capacity and to charge a fixed fee for retail space, the size of the mall depends critically on the search cost. For very small search costs the optimal mall size is increasing in search costs. If search costs are moderately small, the largest marketplace absorbs all the firms in the industry. Such concentration is typical for online markets with low search frictions. However, as search costs increase, the optimal size of the marketplace decreases monotonically. Hence, in off-line markets i.e., those with brick-and-mortar stores and large search costs, we predict that intermediate levels of concentration will prevail.

Since consumer search in our paper is driven by the size of the marketplace, our paper contributes to the recent research on directed or ordered search and prominence ${ }^{1}$. An article by Arbatskaya (2007) first proposed a search protocol in which consumers search in a certain specified order, finding that firms which are visited earlier charge higher prices. This result was subsequently reversed in a sequence of papers which, along with ours, build upon the model of differentiated products proposed by Wolinsky (1986) and Anderson and Renault (1999). Zhou (2011) proposed a model of ordered search with differentiated products. In his paper, any search order can be rationalized as an equilibrium: firms visited earlier set lower prices, hence they should indeed be visited first (due to the Weitzman (1979) search rule). This means that if there are $n$ firms in the industry, there are $n$ ! possible equilibria (or more if one allows for mixed search strategies). This arises because there is only one force affecting the price, the elasticity of demand, which drops with each search round. In our paper the prices also increase in search order, but as a consequence of many factors. As sampling order is defined by the size of the marketplace, marketplaces visited earlier are characterized by a larger variety of products and tougher competition, which pushes prices down even further. For some

\footnotetext{
${ }^{1}$ See Armstrong (2017) for a detailed discussion of this literature.
} 
specific market configurations (partitions of the firms into marketplaces) other equilibria may exist. However, the equilibrium we characterize is the only robust equilibrium, in the following sense: there are no market configurations for which the decreasing-search-order equilibrium does not exist, and there are market configurations, for which only equilibria with decreasing search order exist.

Our paper is also related to the literature on prominence. In this literature, firms are ranked by their prominence in search order, either exogenously as in Armstrong et al. (2009) or endogenously via position auctions (Athey and Ellison (2011)), commissions to salesmen (Armstrong and Zhou (2011)), or stochastically via advertisements (Haan and Moraga-González (2011)). In contrast, a firm achieves prominence in our model by locating in a larger mall or platform.

We show that although competition in large marketplaces is very strong which leads to low prices, firms earn higher profits in such places. The reason is that demand drops swiftly when moving down to smaller malls. This result is similar to that in Zhou (2011), although it is harder to achieve in our case due to the strong competition within large marketplaces. Our result implies that firms prefer to be located in the places with toughest competition which is a counterintuitive conclusion for models without directed search.

The closest paper to ours is Moraga-González and Petrikaitè (2013). In this paper, the authors consider the incentives of firms to merge and sell multiple products under the same roof. They show that if search costs are sufficiently large, there is an equilibrium in which consumers prefer to start searching from the mall. An important difference with our model, however, is that in Moraga-González and Petrikaitè (2013) prices are not set independently, but coordinated instead by a single parent entity. This means that unlike in our model, prices in the mall are higher than in stand-alone stores, making it harder to sustain the descending search order. Our results are clear cut: grouping firms under the same roof increases competition, lowers prices, and makes the descending search order attractive for consumers.

There is extensive literature on firm concentration and clustering, pioneered by Eaton 
and Lipsey (1979), Stahl (1982), and Wolinsky (1983). Dudey (1990) considered a Cournot model with search frictions and showed that there is an equilibrium in which all firms cluster in the same marketplace. In this literature, the closest papers to ours are Fischer and Harrington (1996) and Non (2010). Fischer and Harrington (1996) consider a model in which consumers search for a differentiated product and firms choose whether to locate in a single shopping mall or on the periphery. Due to the assumption of heterogeneous search costs, which are lower for the periphery stores than for the mall, they obtain the result that under free entry some firms cluster (but not all). In our paper this result is reversed if search costs are sufficiently high or the market size is sufficiently large. Moreover, unlike in our paper, in Fischer and Harrington (1996) the incentives to cluster are higher for more differentiated products. Another difference between the two papers is that we are able to deal with fully rational consumers, while in Fischer and Harrington (1996) consumers naively assume there exists an infinite number of stand-alone stores while searching. Once we allow marketplaces to charge a price for retail space, an industry structure similar to Fischer and Harrington (1996) can arise, provided that search costs are sufficiently high. Thus, depending on parameters, either Dudey's (1990) result of pure clustering, or Fischer and Harrington's (1996) core-periphery result can arise in our model. Non (2010) also studies the incentives of firms to locate in malls in the presence of search frictions. She considers a homogeneous goods search model based on Stahl (1989) and, similarly to Fischer and Harrington (1996), an industry with just one large marketplace and a periphery of stand-alone stores. She looks at an equilibrium in mixed strategies in which, as in our paper, stand-alone stores tend to charge higher prices.

Finally, our paper is related to the literature on platform competition, as a marketplace in our paper can be viewed as a selling platform. However, unlike most of the literature (e.g. Armstrong (2006)), we abstract from the question of optimal platform pricing, and assume that retail space at each marketplace is sold at a fixed price, which does not affect the marginal costs of the firms. Because our main motivating example is brickand-mortar shopping malls, we assume, unlike Baye and Morgan (2001) or Galeotti and 
Moraga-González (2009), that the marketplace does not charge consumers for visits. A particular case of our main result with a single platform and a fringe of stand-alone stores resembles the full participation subgame which arises in Galeotti and Moraga-González (2009). A paper by Wang and Wright (2016) has many features in common with ours: they assume that searching within the platform involves lower search costs, and that consumers decide whether to search directly or via the platform. However, there are notable differences. Firstly, they consider a model with an infinite number of firms, which simplifies the analysis, but makes it impossible to analyse a general market structure with platforms of different sizes. Second, they allow for multi-homing and concentrate on the analysis of show-rooming and price parity practices, while we consider single-homing firms (see the discussion of incentives for firms to multi-home in Section 5) and focus on the characterization of pricing and profit ranking in a general finite setting. Finally, Song (2014) has a structure similar to our model where he considers a single large marketplace comparable to that discussed in Section 4. The primary difference between our model and Song's is that he assumes that there are infinitely many firms outside the platform, which effectively implies that off-platform profits are equal to zero. Instead, we look at a finite number of firms and show that, opposite to Song (2014), firms might have incentives to locate outside the platform when search frictions are small enough.

The rest of the paper is organized as follows. In Section 2 we describe the model. In Section 3 we derive the optimal stopping rule, characterize the market equilibrium and show its robustness. Section 4 provides results on the incentives of firms to join a marketplace, optimal pricing of the retail space, and the optimal size of the shopping mall. Section 5 is devoted to a discussion of the role of our assumptions and conclusions. All proofs can be found in the Appendix. 


\section{Model}

We consider an industry with $n$ firms selling a differentiated product to consumers. Firms produce their products at zero marginal cost and compete in prices. There is a unit mass (a continuum) of consumers in the market. Each consumer demands exactly one unit of the product. The utility of consumer $i$ from buying a product of firm $j$ is $U_{i}=u_{i j}-p_{j}$, where $u_{i j}$ is a match value between consumer $i$ and brand $j$, and $p_{j}$ is the price charged by firm $j$. We assume that $u_{i j}$ is distributed uniformly and independently (both across consumers and across firms) on $[0,1]$. When talking about the representative consumer, we drop the subscript $i$. We assume that if a consumer does not buy the product her utility is zero.

We assume that each firm sells its product in a single marketplace (single-homing). Marketplaces can either be on-line selling platforms or shopping malls. Of course, a firm might choose not to join any platform or mall, but rather sell its product via its own web-site or store. We refer to such firms as stand-alone sellers or marketplaces of size one.

Suppose that marketplaces can be of $K<n$ different sizes. Suppose that for any $k=1, \ldots, K$ there are $M_{k}$ marketplaces of size $N_{k}, \sum_{k=1}^{K} N_{k} M_{k}=n$. We refer to a group of marketplaces of the same size as a cohort. We order cohorts in such a way that $N_{k}>N_{l}$ for $k<l$, so $N_{1}$ is the size of the largest marketplace(s), and $N_{K}$ is the size of the smallest one(s). We refer to the pair of vectors $\left\{\left(N_{1}, \ldots, N_{K}\right),\left(M_{1}, \ldots, M_{K}\right)\right\}$ as the market configuration, i.e. the partition of the set of firms among malls of different sizes. In this paper we focus on symmetric pricing equilibria, i.e. equilibria such that all firms belonging to marketplaces of the same size charge the same price.

Consumers engage in costly search. We assume that once a consumer enters a marketplace she learns all the prices and match values in this marketplace without incurring any cost. If, however, she decides to leave the mall and search in another marketplace, we assume that she bears a search cost of $s \leq 1 / 8$ each time she does so $^{2}$. We assume that

\footnotetext{
${ }^{2}$ This condition guarantees that consumers prefer checking stand-alone firms to leaving the market, even when such firms charge the monopoly price. Naturally, this also guarantees full participation in the
} 
consumers are aware of the size of each marketplace and can direct their search activity based on this information. We also make an assumption of costless return: consumers can come back to previously visited marketplaces for free. This assumption is natural for online shopping, where the main part of search cost is time and effort spent on getting acquainted with the interface of each platform, but is less plausible in case of brickand-mortar malls, when search costs are mainly transportation costs. This assumption is common in the consumer search literature as it simplifies the analysis considerably, making reservation utilities stationary (in our case, when searching within a single cohort), and, as Janssen and Parakhonyak (2014) suggest, should not change our results qualitatively.

\section{Analysis}

\subsection{Optimal Stopping}

We construct an equilibrium in which consumers start searching from within the cohort of largest marketplaces (of size $N_{1}$ ), then move to the second largest marketplaces and so on. Within each cohort we assume a random search procedure: as consumers cannot distinguish among marketplaces of the same size, ex ante there is no reason to assume any specific search order. As we will show, there are two incentives to employ this search rule: in larger malls consumers expect to find a better match than in smaller ones, and it turns out that in equilibrium marketplaces that come first in the search order set lower prices than those which are visited later. For some specific market configurations, it is possible to find other equilibria. For example, if there are just two marketplaces of almost the same size, the price effect can be stronger than the variety effect and it might be possible to find an equilibrium with the reverse search order. However, the proposed search rule, first search round. See Janssen et al. (2005) for a discussion of consumer participation in the case of homogeneous goods and Moraga-González et al. (2017) for the case of differentiated products and search cost heterogeneity. 
according to which consumers go from the largest to the smallest marketplaces, is the only one which is robust to any market configuration: for any pair of vectors $\left(N_{1}, \ldots, N_{K}\right)$ and $\left(M_{1}, \ldots, M_{K}\right)$ such that $\sum_{k=1}^{K} M_{k} N_{k}=n$, there is always an equilibrium in which the largest-to-smallest search rule is optimal, while other search rules fail to be a part of equilibrium for some $M_{k}$ and $N_{k}, k=1, \ldots, K$ (see Proposition 3 for details).

In order to derive the optimal stopping strategy, we apply the result of Weitzman (1979). Suppose that consumers believe that price of each firm in each marketplace in cohort $i$ is $p_{i}^{e}$, and that $p_{i}^{e} \geq p_{j}^{e}$ for any $i>j$. Later we check that price monotonicity holds in equilibrium. As Weitzman (1979) showed, the optimal stopping rule is to sample options in descending order of their reservation value and terminate search as soon as one of the options delivers utility higher than the largest reservation value of all unsampled options. Let us define $a_{k}, k=1, \ldots, K$ as a solution to the following equation:

$$
\int_{a_{k}}^{1} N_{k}\left(u-a_{k}\right) u^{N_{k}-1} d u=s .
$$

Thus, at $a_{k}$ a searcher is indifferent between accepting $a_{k}$ immediately and sampling an additional $N_{k}$ options at cost $s$. The left hand side of (1) is the expected gain from search, where $u-a_{k}$ is how much more the consumer can gain over the reservation value, and, because $u$ is the best of $N_{k}$ options, it is distributed according to function $F_{k}(u)=u^{N_{k}}$. Define

$$
z_{k}=a_{k}-p_{k}^{e}
$$

$z_{k}$ is the reservation utility for a marketplace of size $k$ given $p_{k}^{e}$. Note that as $p_{i}^{e}>p_{j}^{e}$ and $a_{i}<a_{j}$ for $i>j$, we obtain $z_{i}<z_{j}$. Then, the result of Weitzman (1979) allows us to formulate the following proposition.

Proposition 1 (Weitzman's (1979) Rule). Suppose that the consumer expects an increasing sequence of prices: $p_{1}^{e}<p_{2}^{e}<\ldots<p_{K}^{e}<a_{K}$. Then optimal stopping behaviour is characterised by a decreasing sequence of reservation utilities $z_{1}>z_{2}>\ldots>z_{K}>0$, $z_{k} \equiv a_{k}-p_{k}^{e}$. That is, if $v \equiv u-p$ is the highest utility observed by the consumer so far and $z_{k}$ is the highest reservation utility of the remaining options, then it is optimal to: 
1. terminate search if $v \geq z_{k}$;

2. continue searching at one of the options with reservation utility $z_{k}$ with equal probability if $v<z_{k}$.

This Proposition formally captures the search pattern we consider in our analysis: consumers optimally go to larger malls first and randomize among malls of the same size with equal probability. Of course, it is possible to consider the case of asymmetric optimal stopping rules within cohorts (if there are $L$ options with the largest reservation utility $z_{k}$, then there are $L$ ! possibilities at each stage), but as there is no reason for consumers to prefer one mall over another of equal size, we stick to the symmetric version of the rule. Now we are ready to move to the analysis of firms' behaviour.

\subsection{Demand and Market Equilibrium}

We start this section with the derivation of the demand functions of the firms. Consider the demand for a firm in cohort $k$ charging a price $\hat{p}_{k}$, while other firms in cohort $j \leq K$ charge price $p_{j}$. There are two sources of demand: fresh demand, i.e. consumers who visit the firm for the first time and decide to stop there, and returning demand, i.e. consumers who previously visited the firm, did not find the offering attractive enough to stop at the time, but decided to return later on. For purely expositional purposes in our derivation of demand, we make the following adjustment. For any firm $j$ and any consumer $i$, there is a chance that firm $j$ is located in the mall which is visited by consumer $i$ last among $M_{k}$ malls in cohort $k$. If the net utility the consumer gets is sufficiently high to stop even if this marketplace was not the last in the cohort $\left(u_{i j}-\hat{p}_{k} \geq z_{k}\right)$, we classify consumer $i$ 's demand as fresh. If the deal was less attractive, but still sufficiently good not to move to cohort $k+1\left(z_{k}>u_{i j}-\hat{p}_{k} \geq z_{k+1}\right)$, we term such demand as returning (from other malls

in the same cohort). In our derivations we make the assumption that price deviations are relatively small (whenever it is innocuous), and thus the probabilities of the events under consideration are strictly between zero and one. This allows us to reduce our notation 
considerably and does not have any material impact on the results.

Assuming that all other firms stick to the equilibrium pricing strategies, such that $p_{k}<p_{l}$ for $k<l$, the consumer buys from a firm in cohort $k$ which charges $\hat{p}_{k}$ if the following conditions are met.

1. The consumer decides to search in cohort $k$, thus all $\sum_{j=1}^{k-1} N_{j} M_{j}$ firms provide a match which is worse than the reservation value for cohort $k$, i.e. $u-p_{j}<z_{k}=$ $a_{k}-p_{k}^{e}, j \leq k-1$. This happens with probability

$$
\prod_{j \leq k-1}\left(z_{k}+p_{j}\right)^{N j M_{j}}
$$

which is set to 1 for $k=1$.

2. The firm we consider is reached during the search process in cohort $k$. If the firm is in marketplace $j \leq M_{k}$, it is reached if all other firms provide utility $u-p_{k}<z_{k}$. So, the probability that a firm at a random marketplace in cohort $k$ is reached equals to

$$
\frac{1}{M_{k}} \sum_{j=1}^{M_{k}}\left(z_{k}+p_{k}\right)^{(j-1) N_{k}} .
$$

Note that because the consumer randomizes between malls of the same size, the firm under consideration will be in $j^{\prime}$ th $\left(j=1, \ldots, M_{k}\right)$ mall in her search order with probability $1 / M_{k}$.

3. Finally, the consumer wants to buy from the firm under consideration, provided that she reaches its marketplace. This implies that the consumer does not want to continue her search to further marketplaces $\left(u-\hat{p}_{k} \geq z_{k}\right)$ and all other firms at the same marketplace (keeping in mind that the search is free within the marketplace) provide lower utility: $u-\hat{p}_{k} \geq \max _{i \leq N_{k}-1} u_{i}-p_{k}$, which gives the following expression for the probability:

$$
\int_{z_{k}+\hat{p}_{k}}^{1}\left(\min \left\{u-\hat{p}_{k}+p_{k}, 1\right\}\right)^{N_{k}-1} d u .
$$

Thus, fresh demand can be written as 


$$
\begin{array}{r}
f_{k}\left(\hat{p}_{k}\right) \equiv\left[\prod_{j \leq k-1}\left(z_{k}+p_{j}\right)^{N j M_{j}}\right]\left[\frac{1}{M_{k}} \sum_{j=1}^{M_{k}}\left(z_{k}+p_{k}\right)^{(j-1) N_{k}}\right] \\
\cdot \int_{z_{k}+\hat{p}_{k}}^{1}\left(\min \left\{u-\hat{p}_{k}+p_{k}, 1\right\}\right)^{N_{k}-1} d u .
\end{array}
$$

We denote

$$
h_{k} \equiv\left[\prod_{j \leq k-1}\left(z_{k}+p_{j}\right)^{N j M_{j}}\right]\left[\frac{1}{M_{k}} \sum_{j=1}^{M_{k}}\left(z_{k}+p_{k}\right)^{(j-1) N_{k}}\right] .
$$

Note that $h_{k}$ does not depend on the firm's own price, $\hat{p}_{k}$, since $h_{k}$ is simply the probability that all previously visited malls did not provide a satisfactory match.

Now consider a consumer, who visited the firm charging $\hat{p}_{k}$ in cohort $k$ and decided to return to buy after sampling cohort $i$. Because this consumer reached cohort $i$, it must be the case that $u-\hat{p}_{k}<z_{i}$. Because the consumer decided not to move to cohort $i+1$ and go back to the firm under consideration, it must be the case that $u-\hat{p}_{k}>z_{i+1}$. Moreover, the consumer returns to the firm which provides the best utility. Thus, the returning demand is

$$
\sum_{i=k}^{K} \int_{z_{i+1}+\hat{p}_{k}}^{z_{i}+\hat{p}_{k}}\left[\prod_{j \leq i, j \neq k}\left(u-\hat{p}_{k}+p_{j}\right)^{N_{j} M_{j}}\right]\left(u-\hat{p}_{k}+p_{k}\right)^{N_{k} M_{k}-1} d u
$$

where we set $z_{K+1}=0$ to reflect that the outside option gives zero utility. The expression for the returning demand can be rewritten as

$$
r_{k} \equiv \sum_{i=k}^{K} \int_{z_{i+1}}^{z_{i}}\left[\prod_{j \leq i, j \neq k}\left(u+p_{j}\right)^{N_{j} M_{j}}\right]\left(u+p_{k}\right)^{N_{k} M_{k}-1} d u .
$$

Returning demand does not depend on the firm's own price - this is a well known feature of the Wolinsky (1986) model with the uniform distribution of match values. As own price is reduced, two opposite effects take place: on the one hand, fewer people walk away from the offer as it becomes more attractive at first glance; on the other hand, the firm gets back a higher share of consumers who walk away. Under the uniform distribution, 
these two effects cancel each other out ${ }^{3}$.

Total demand of a firm in cohort $k$ can be rewritten as

$$
D_{k}\left(\hat{p}_{k}\right)=r_{k}+h_{k} \int_{z_{k}+\hat{p}_{k}}^{1}\left(\min \left\{u-\hat{p}_{k}+p_{k}, 1\right\}\right)^{N_{k}-1} d u .
$$

Note, that $\hat{p}_{k}$ appears only in the integral term, which allows for a relatively simple analysis of the firm's problem.

The profit of a firm in cohort $k$ can now be written as

$$
\pi_{k}\left(\hat{p}_{k}\right)=\hat{p}_{k} D_{k}\left(\hat{p}_{k}\right)
$$

Now we are ready to derive the market equilibrium of the model. In equilibrium, the profit-maximizing price $\hat{p}_{k}$ must be equal to $p_{k}$, the equilibrium price of a firm located in a marketplace in cohort $k$.

Proposition 2. For any search cost and any market configuration there exists a market equilibrium such that each firm in cohort $k$ sets a price implicitly defined by

$$
p_{k}=\frac{1-a_{k}^{N_{k}}}{N_{k}}+\frac{r_{k}}{h_{k}}
$$

with $p_{k} \in\left[\frac{1-a_{k}^{N_{k}}}{N_{k}}, \frac{1-a_{k}^{N_{k}}}{N_{k}\left(1-a_{k}\right)+1-a_{k}^{N_{k}}}\right] \subset\left[0, \frac{1}{2}\right]$. In this equilibrium $p_{i}<p_{j}$ for all $i<j$ and consumers follow the descending optimal stopping strategy defined in Proposition 1.

This result shows that despite having larger demand, firms in larger marketplaces set lower prices. One reason is that demand in larger malls is more elastic because consumers have more options to explore, while in the malls visited later it is apparent that previous searches were not successful and there are fewer options left. Moreover, prices in larger marketplaces are driven down by stronger competition within the mall. This price monotonicity, together with the monotonicity of reservation utilities $a_{k}$, creates

\footnotetext{
${ }^{3}$ For other distributions, returning demand will depend on own price, making the analysis more complicated. We calculated the solutions numerically for the power distribution of consumer valuations $F(u)=u^{\alpha}$ with $\alpha>0, \alpha \neq 1$, and all our conclusions remained unchanged.
} 
a very strong incentive for consumers to search in a descending order of marketplace size. This result is similar to the one obtained in Zhou (2011). However, there is an important difference in our results. In his paper, any search order can be a part of equilibrium, as firms which are searched earlier always set lower prices. This is due to the fact that in his model the price monotonicity is driven only by the demand elasticity effect, but the competitive force is not present. This gives $n$ ! possible equilibria in pure search strategies and even more if consumers decide to randomize over a certain subset of firms. In our case, the search order is determined not only by prices, but also by the number of options available at the marketplace. Furthermore, a larger marketplace could have lower prices even if it was not the first in the search order because of stronger competition within such a marketplace. Thus, although for particular market configurations (typically those with few marketplaces of approximately equal size) one can construct an equilibrium where the search order is not descending in marketplace size, our equilibrium is the robust one. This means that for any given market configuration there is an equilibrium as defined in Proposition 2, while equilibria with a non-descending order fail to exist for some market configurations, typically with large differences in the size of marketplaces. This intuition is formally captured by the following Proposition.

Proposition 3. For any search cost there exists a market configuration such that equilibria in which smaller marketplaces are visited before the larger ones do not exist.

As only one equilibrium is robust to the market configuration, in further analysis we concentrate on the properties of this equilibrium ${ }^{4}$.

We know from Proposition 2 that prices are lower in larger marketplaces, but that such

\footnotetext{
${ }^{4}$ This equilibrium is not only robust with respect to market configuration, but also to the level of the search frictions. To see this, consider the case in which the search frictions are large, and approach the level for which only consumers with non-positive option continue searching, and thus the returning demand does not exist. In this case, larger marketplaces are always the best option, as variety and competitive effects favour larger marketplaces and the demand elasticity effect is not present. However, it is difficult to say precisely how large the search cost must be, as it depends on the particular market configuration. For the case of two malls we established numerically that $s<1 / 16$ is a sufficient condition
} 
marketplaces attract more consumers. Thus, the firms' profit ranking of the marketplaces is not immediately clear. The following Proposition claims that the positive effect due to higher demand is stronger than the negative effect due to stronger competition.

Proposition 4. In the descending search order equilibrium, firms in cohort $k$ earn profits

$$
\pi_{k}=p_{k}^{2} \cdot h_{k}
$$

Furthermore, firms in larger marketplaces attain higher profits, i.e. $\pi_{i}>\pi_{j}$ for $1 \leq i<$ $j \leq K$.

Thus, any firm at a smaller marketplace would rather swap places with a firm at the largest marketplace, meaning that firms prefer to be at the marketplace with the toughest price competition. This somewhat counter-intuitive result is purely a consequence of the directed search protocol: gains from higher demand (increased $h_{k}$ ) outweigh losses from stronger competition and larger demand elasticity (lower $p_{k}$ ).

Notably, as the search cost approaches zero, prices in our model and prices in the Wolinsky (1986) model with $N$ firms converge to the same (positive) value. However, for $s>0$ the limiting properties deserve some extra discussion. From Proposition 2 it follows that prices in the largest mall(s) approach zero as the size of the mall approaches infinity:

$$
\lim _{N_{1} \rightarrow \infty} p_{1}=0
$$

This result follows directly from the fact that the upper bound of $p_{1}$ approaches zero as $N_{1}$ approaches infinity. Moreover, a similar result can be obtained for marketplaces, which are not of the largest size. Formally, for any $m \leq K$ take a sequence of mall size vectors $\left\{\left(N_{1}+l, \ldots, N_{m}+l, N_{m+1}, \ldots, N_{K}\right)\right\}_{l=0}^{\infty}$. Then, for any $k \leq m$ we obtain $\lim _{l \rightarrow \infty} p_{k}=0$. Thus, unlike in Wolinsky (1986) firms do not retain the market power as the number of firms in the marketplace increases without bound. The reason is that in our case the search cost within the marketplace is zero, which leads to exhaustive for non-existence of the inverse search order, but in general we were not able to guarantee that this critical $s$ is within the admissible range of search costs $(s \leq 1 / 8)$. 
competition. However, if the number of firms in the market increases not via increasing the size of marketplaces, but rather via increasing the number of them, each price is still bounded away from zero. Therefore, the competitiveness of the market cannot be judged by merely looking at the number of firms, the market configuration itself plays a crucial role here.

From the consumers' point of view, the optimal market configuration is the one where all firms are located in a single grand marketplace. This allows for savings to be made on search costs, improves the expected quality of match and leads to lower prices, thereby increasing consumers' participation. As we have unit demand, the price is just a transfer between consumers and firms. Thus, total welfare is also maximised when all firms are located in the same mall.

\section{Industry Structure}

Now we look at incentives of the firms to join a mall. In order to obtain clear-cut results, we concentrate on a specific industry structure: we look at a single mall with a fringe of stand-alone stores. The equilibrium industry structure depends on assumptions about the market for retail space. We look into two possibilities of market formation: when firms are free to choose their location either in the mall or outside, and when the marketplace can choose its size and charge a fixed entry fee.

\subsection{Free Entry}

We start our analysis with the free entry model. Suppose that there is a single mall of size $N \geq 2$ along with $M \geq 0$ stand-alone stores. Then the following Lemma holds.

Lemma 5. Suppose consumers start searching in the mall. Then for any search cost, there is a unique symmetric pricing equilibrium such that:

1. prices of all firms are increasing in s; 
2. profit of firms in the mall is non-decreasing in s;

3. if $M=1$ then there is a unique $s_{0}$ such that the profit of the stand-alone firm is increasing in $s$ for $s \leq s_{0}$ and decreasing in $s$ for $s>s_{0}$.

Now, suppose that all firms are located in a single large mall and there is a single entrant, which decides whether to co-locate with other firms or enter as a stand-alone store. The last statement of Lemma 5 guarantees that for small $s$ the entrant wants to be outside the mall. If instead it enters the mall, its profit would not depend on $s$, because there are no firms outside the mall and search costs inside the mall are zero. Also, observe that at $s=0$ a firm is indifferent between entering the mall and locating outside. Thus, for $s<s_{0}$ it must be the case that the firm attains higher profit by being stand-alone. Now, we also claim that for sufficiently large $s$ (close to 1/8) the entrant prefers to enter the mall. Note that if $s=1 / 8$ there is no returning demand from the stand-alone firm, as consumers only leave when their surplus is negative. It is easy to see that the price in a mall with $N$ firms satisfies the following expression ${ }^{5}$ :

$$
N p_{1}(N)=1-\left[p_{1}(N)\right]^{N}
$$

Using (8), profit of a firm is $\pi_{1}=\left[p_{1}(N+1)\right]^{2}$ if it enters the mall, and $\pi_{2}=\frac{1}{4}\left[p_{1}(N)\right]^{N}$ if it enters as a stand-alone. Now, note that

$$
\begin{aligned}
\pi_{1}=\left[p_{1}(N+1)\right]^{2}>\left[p_{1}(N+1)\right]^{N}>\left[\frac{N}{N+1} p_{1}(N)\right]^{N} & = \\
& {\left[\left(1-\frac{1}{N+1}\right) p_{1}(N)\right]^{N}>\frac{1}{e}\left[p_{1}(N)\right]^{N}>\frac{1}{4}\left[p_{1}(N)\right]^{N}=\pi_{2} . }
\end{aligned}
$$

The second inequality comes from the fact that $N p_{1}(N)<(N+1) p_{1}(N+1)$, which in turn follows from the fact that price is decreasing in $N$ and equation (9). Because, according to

\footnotetext{
${ }^{5}$ Coincidentally, this $p_{1}(N)$ is also the Wolinsky monopolistic competition price with $N$ firms and zero search costs. It is a well-known feature of ordered search models that at $s=1 / 8$ firms act as monopolists. In the mall-fringe model, this result is generalized to stand-alone stores charging the monopoly price, and the mall charging the monopolistic competition price.
} 
Lemma 5, the profit of a stand-alone firm is a single-peaked function of $s$, there must be a unique value of the search friction $s_{1}$, such that the firm prefers to enter the mall if the search cost does not exceed this value. Thus, we can formulate the following proposition.

Proposition 6. Assume there is a single marketplace with $N \geq 2$ firms. Then, there exists a unique $s_{1} \in(0,1 / 8)$ such that if $s<s_{1}$ an entrant firm prefers to locate outside the mall, and for $s>s_{1}$ it prefers to join the mall.

The intuition behind this result is as follows. For $s=0$ there is no difference between being in the mall or outside. If $s$ is positive, there are two opposite forces affecting the profit. The first, direct, force is that the firm is not reached by all customers and thus its profit is pushed down. The second, indirect force, is that because the firm is outside the mall, its competitors in the mall price less aggressively, which leaves the outsider firm with demand high enough to charge higher prices $^{6}$. The second force dominates only when the search friction is very small. If the mall is sufficiently large and prices are already quite competitive there, the second effect almost disappears. The same applies to the case of multiple stand-alone firms, although we obtained this result only numerically: the critical value of $s_{1}$ decreases in $M$.

Note that Proposition 4 suggests that being in the mall is more attractive. However, this result is valid only for a fixed industry structure; entry affects the profits of the firms located in the mall. Although for any market structure the firms in the mall earn higher profit, there is no guarantee that the profit of the firms in the mall after a firm enters in there would be higher than the profit of a stand-alone store after a firm enters as such a one. Proposition 6 illustrates this subtle difference. The literature on directed search and prominence generally argues that coming first in the search order is beneficial for

\footnotetext{
${ }^{6}$ This result resembles the one of Wilson (2010), where one of the firms chooses to fully obfuscate (set high search costs). The difference with our model is that in Wilson (2010) such a firm hopes to sell only to shoppers (consumers with zero search costs), while in our model with differentiated products a stand-alone store serves consumers with positive search frictions who have not found an acceptable match in the mall.
} 
firms ${ }^{7}$. This result also holds in our case (see Proposition 4), but only for a fixed market configuration. That is, each firm in a smaller marketplace would rather swap its position with a firm in a larger one. However, if there is a new entrant, its entry would affect the market configuration, and it might actually prefer to locate outside the mall and thus come later in the search order. Interestingly, in our model firms may locate outside the marketplace even if it does not charge any entry fees, like in Baye and Morgan (2001) or Galeotti and Moraga-González (2009).

\subsection{Selling Retail Space}

Now we turn our attention to a situation in which a marketplace can charge a price for its retail space. Again, we assume that there is a single large shopping mall and a fringe of stand-alone firms. Suppose the mall can decide on the number of firms it accepts and the price it charges for its retail space. Again, denote the number of firms in the mall by $N$ and the number of stand-alone firms by $M$. Denote the profit of a firm which operates in the mall and as stand-alone as $\pi_{1}(N, M)$ and $\pi_{2}(N, M)$, respectively. Suppose the mall reaches $N$ out of $N+M$ firms and offers them a place at price $p$. There is an equilibrium in which $N$ firms join the mall as long as

$$
\pi_{1}(N, M)-\pi_{2}(N-1, M+1) \geq p
$$

Therefore, the mall can collect a total profit of

$$
\Pi_{\text {Mall }}=N\left[\pi_{1}(N, M)-\pi_{2}(N-1, M+1)\right]^{8} .
$$

It turns out that the mall's profit maximization problem is much harder than the one of a single firm. This is due partly to the discrete nature of the strategic variable, namely the number of firms. Thus, we analyze the mall's problem numerically.

\footnotetext{
${ }^{7}$ The only exception known to us is Fishman and Lubensky (2017), where the existence of returning costs can make it attractive to be visited later.

${ }^{8}$ The delicate moment is when the mall size changes from one to two. In numerical computations we have assumed that the mall stays prominent, even if it consists of only one firm, but assuming random search gives similar results: only the cut-off between two and three firms differs.
} 
Figure 1: Mall profit as a function of its size (the total number of firms is 20).
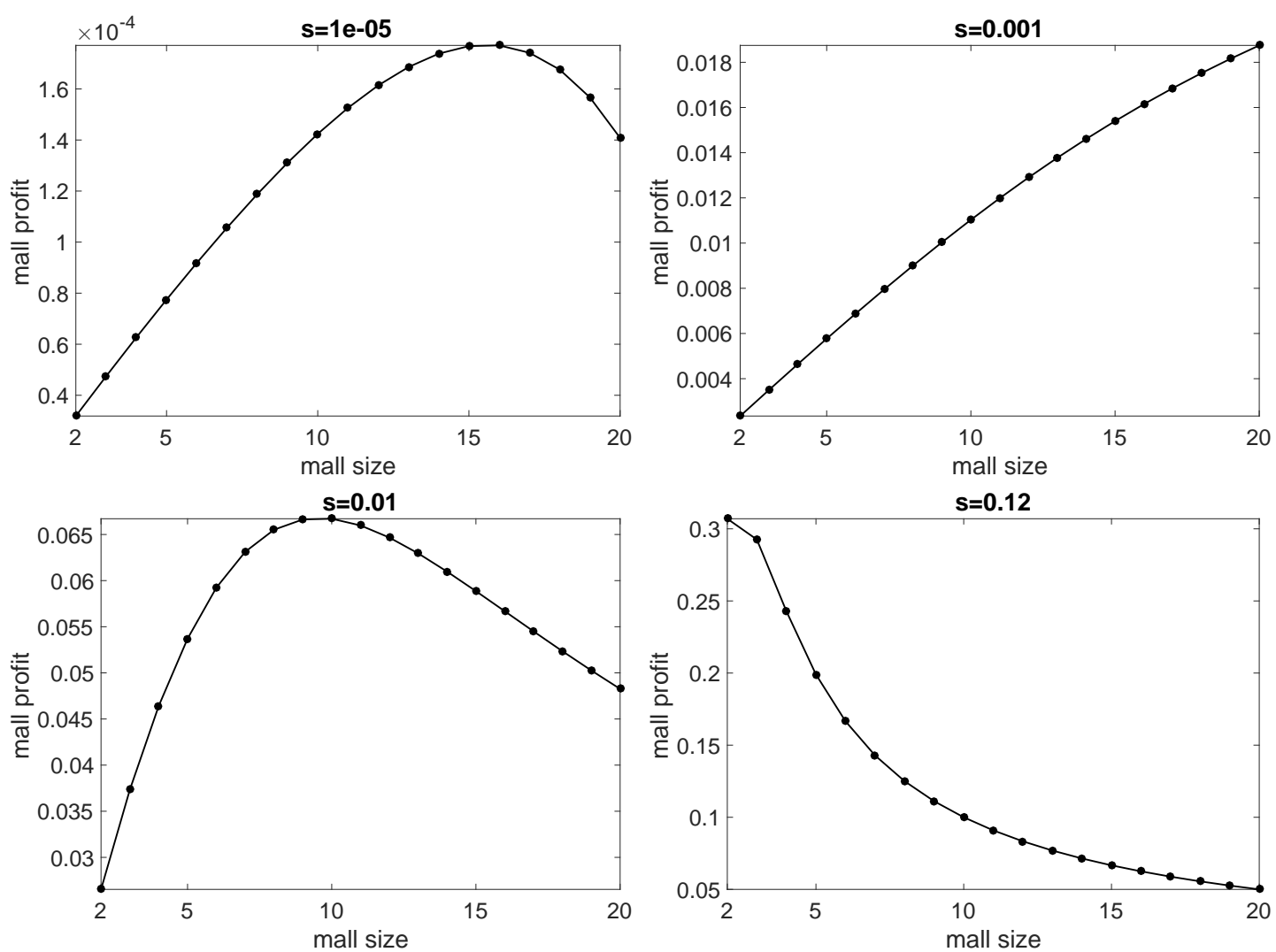

Figure 1 illustrates how the profit of the mall depends on the number of firms in the mall for various values of the search cost $s$. As we know from the previous analysis of the free entry case, when search costs are very small (in the order of $s=1 / 100,000$ in our case) firms prefer to be stand-alone. Thus, the mall prefers to limit its size (as otherwise it has to pay for the firms to come in if it wants many of them). When search frictions are moderately small $(s=0.001)$ the situation changes sharply and mall's profit increases in the number of firms, i.e. the large marketplace tends to absorb the whole market. This happens because for these moderately small search costs many consumers search beyond the mall, which implies that the difference between the profits of firms inside and outside the mall is not that high, and moreover both these profit levels are relatively low. At the same time the search friction is high enough (i.e. $s>s_{1}$ as specified in Proposition 6) to make being in the mall attractive. In this case, adding an extra firm to the mall does not 
shift retail prices too much. Therefore, the price charged for retail space is not sensitive to the number of firms in the mall. This situation is typical for online markets in which many sellers trade in the same marketplace, for example, eBay. If search costs are high $(s=0.12)$ shopping malls tend to stay small. The reason is that high search costs protect firms inside the mall from outside competition. Thus, retail prices in the mall are very sensitive to the number of firms which means that the price of retail space is very elastic. In this case, the mall wants to keep its position at the top of the search order, which is achieved with $N=2$. This situation is typical for markets with brick-and-mortar stores and high search or transportation costs. For moderate values of search costs, for example $s=0.01$ in Figure 1, malls tend to be of an intermediate size. Figure 2 summarizes the aforementioned discussion by depicting the optimal number of the firms in the mall as a function of search costs.

Figure 2: Optimal mall size as a function of search cost, total number of firms equals 20.

(a) Full Search Cost Range

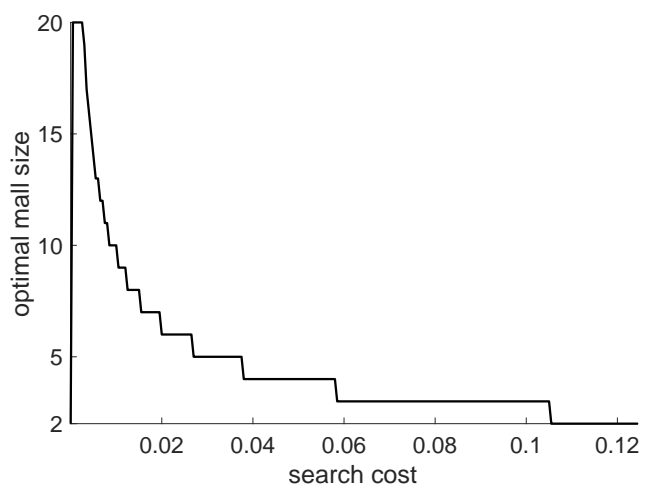

(b) Small Search Costs

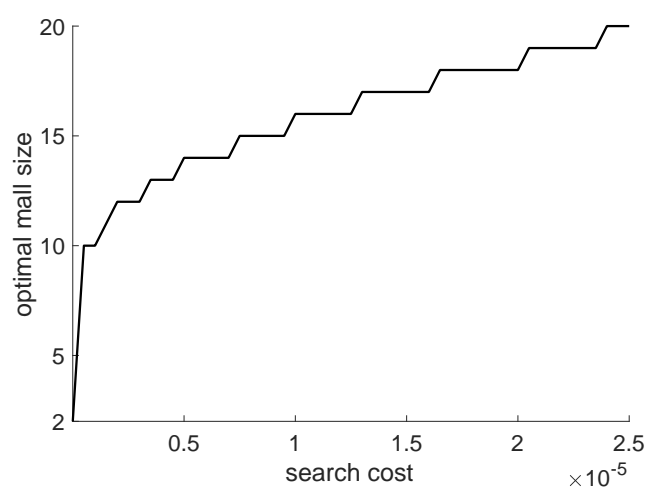

Note that in case of endogenous mall pricing, the negative impact of search frictions affects social welfare in a novel way. In standard settings, higher search costs lead to higher prices and reduce the quality of matching, but in our case, except for the lowest search cost levels, this is accompanied by a decrease in mall size, and thereby a weakening of competition. Profits exhibit non-monotone behaviour. As $s$ increases, the profit of a firm in the mall increases, while the profit of a stand-alone firm goes down. At some 
point, the mall finds it optimal to reduce its size and weaken competition, which means that profits of both types of firms go up (except for the firm leaving the mall). As $s$ grows further, this process, as shown on Figure 3, repeats itself ${ }^{9}$.

Note that if entry as a stand-alone firm involved sufficiently high fixed costs, higher search costs might lead to the exit of stand-alone stores ${ }^{10}$. Consider the right-hand panel of Figure 3. For $s \in[0.06,0.09]$ the profit function of a stand-alone firm is decreasing in $s$, and provided that the fixed cost of running stand-alone store is sufficiently large, say, $1 \times 10^{-3}$, firms will leave the market if search costs increase. Moreover, if, for example, $s=0.1$ the mall might want to accommodate more firms than it is optimal to have in the absence of fixed costs, so the rest of the stand-alone firms are pushed out of the market.

Figure 3: Mall profit, profit of a firm in the mall and stand-alone firms as a function of $s$ $(N+M=20)$.
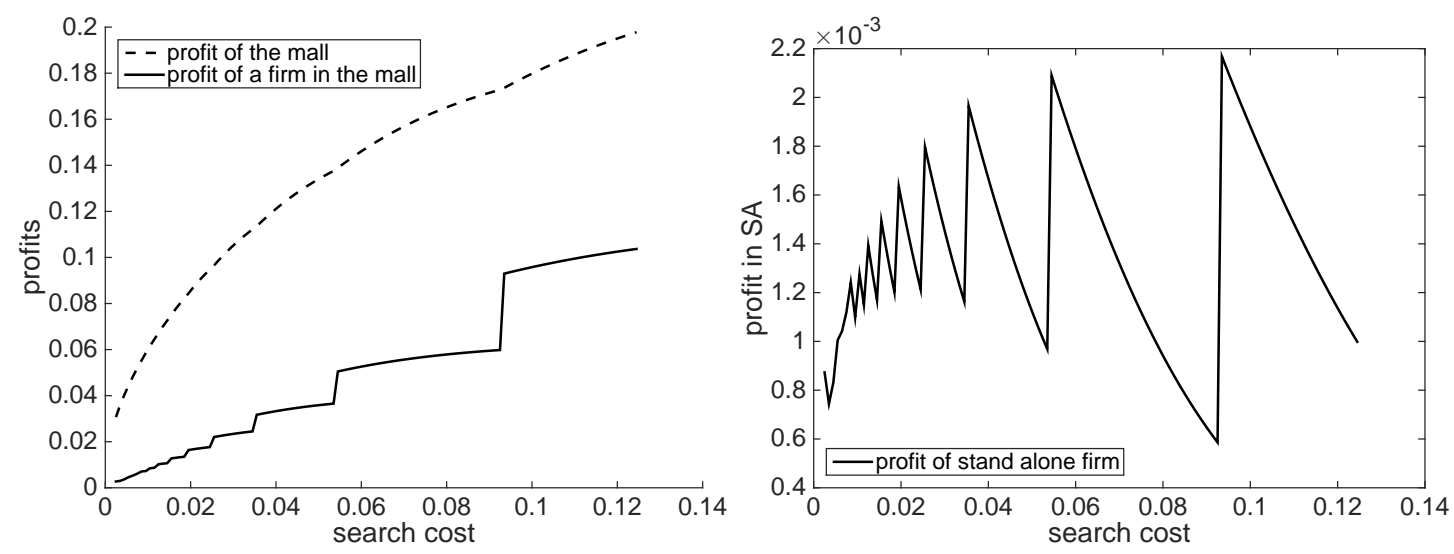

Song (2014) considers the case in which the number of firms outside the shopping mall is infinite. In that case, there is no returning demand and the problem becomes much simpler ${ }^{11}$. Moreover, because there is a finite number of firms on the platform, and an

\footnotetext{
${ }^{9}$ For small $s$, we get a mirror image of this result: and the mall size increases in search cost.

${ }^{10}$ We thank an anonymous referee for pointing this out.

${ }^{11}$ Rhodes et al. (2017) also consider a setting with a continuum of manufactures and one big retailer. There are two crucial differences between their paper and ours: (i) consumers in their model buy all products that give them positive surplus rather than search for the best match, (ii) products in their
} 
infinite number of firms outside, demand per firm outside of the platform is negligible in comparison with the demand received by firms inside. As a result, the platform maximizes the total profit obtained by $N$ firms which are offered to join. In Proposition 3 of his paper, Song (2014) shows that there is an optimal platform size, which is inversely related to the size of search friction $s$. This is similar to our results obtained for sufficiently large search frictions. However, when the search friction is low enough (below $2.5 \times 10^{-5}$ in Figure 2), the finiteness of our model kicks in: the optimal mall size is increasing in $s$, and mall's profit is a single-peaked function of $N$, as depicted on the first panel of Figure 1. In Song (2014), as search frictions approach zero, the optimal mall size approaches infinity, thus the mall's profit function is similar to the one depicted in the second panel of Figure $1(s=0.001)$.

\section{Discussion and Conclusions}

In this section we discuss the role of our assumptions and the economic implications of our analysis.

In our model we assumed that match values are uniformly distributed. As in the analysis of Moraga-González and Petrikaitè (2013), using alternative distributions is likely to yield similar results. The main purpose it serves is that the returning demand does not depend on the firm's price, which considerably simplifies derivations, but does not have any material impact either on search or on pricing strategies.

The second important assumption is that there are no search frictions when consumers search within the mall. Some modelling settings necessarily require positive search frictions at the shopping malls or platforms either due to the assumption of homogenous products (Non (2010)) or continuum of firms (Wang and Wright (2016)). In our case however, this assumption is not crucial and our results would be qualitatively similar if there was a positive cost of sampling a firm within each marketplace, provided that it model are ex-ante heterogeneous, i.e. they carry different values to consumers and profits to producers. 
is (i) less than the search cost between the marketplaces and (ii) either constant or decreasing in the size of the marketplace. As the search cost between the malls is higher than within each mall, it is guaranteed that consumers do not come back or move to the next marketplace unless they visit all the firms in the mall. Thus, such a model would not differ from ours in any significant way. The only distinction is that when the search cost within the mall is positive, the price set by the firms does not approach zero as the number of firms at this marketplace approaches infinity. This is a well known result from Wolinsky (1986).

A third assumption we made is perfect recall. This assumption ensures that the reservation utility is constant for any cohort. As Janssen and Parakhonyak (2014) show, the presence of return costs makes search strategies time and path dependent, and the equilibrium price in the Wolinsky (1986) model depends non-monotonically on the return cost. Price monotonicity in marketplace size is reinforced: in the presence of return costs malls coming later in the search order both understand that previous matches were relatively less attractive (in comparison with the case without return costs) and realize that consumers are less likely to go back in the presence of return costs, which implies less elastic demand. As return costs create extra monopoly power, prominence seems to be more important in a model with return costs than in a model without. However, as Fishman and Lubensky (2017) show, for sufficiently low search and recall costs the opposite result can be true: firms can benefit from appearing last in the search order.

A fourth assumption related to search is that there is no differentiation in the cost of sampling different marketplaces. In reality, consumers might prefer to visit marketplaces that are less attractive in terms of offered prices and varieties of products, but are located more conveniently for these particular consumers. Such markets are analyzed in Fischer and Harrington (1996), in which some consumers might prefer to visit periphery firms instead of the cluster. A large fraction of consumers loyal to a smaller mall may reverse our price monotonicity result, provided that the mall is not too small. Moreover, spatial structure of search costs might undermine the single-homing structure of the market, 
which is natural in our model.

A fifth assumption is single-homing, i.e. each firm can sell at one marketplace only. Note that if a firm is located in marketplace $i$ it does not gain anything from being present in marketplace $j>i$, as its match value was already discovered by all the customers who reach step $j$. Moreover, stronger competition leads to lower prices in cohort $i$, so customers would never buy at a store in cohort $j$. Thus, the only gain a firm can get from multihoming is when it locates multiple stores in the first cohort. In this case, the probability that a consumer hits a store belonging to such a firm increases.

We also focused on equilibria in which consumers search randomly within each cohort of marketplaces. This allowed us to combine directed and random search in the same framework. If one assumes that malls in each cohort are visited in some prescribed order, the results would be very similar to those in Zhou (2011): firms in marketplaces visited first set lower prices and earn higher profits. As Proposition 3 suggests, this specific order can be safely introduced only within one cohort but might not be extended for different mall sizes, because then the optimality of this order might be violated.

Finally, we considered a very special platform pricing problem. As long as marketplaces charge firms a fixed fee (regardless of how this is determined), our analysis from Section 4 holds. This fee type is a typical of brick-and-mortar shopping malls. Online platforms usually charge either per click (consumer visit) or per transaction. As seen in Ronayne (2015) and Wang and Wright (2016), per transaction fees effectively shift firm prices upwards, as they increase the marginal cost. Thus, as long as all marketplaces charge the same transaction fee, our analysis holds. However, if larger marketplaces set a higher pertransaction price, the monotonicity of prices is not guaranteed and, thus, the optimality of the search order may break down. However, as any marketplace has strong incentives to be as high as possible in the search order and larger marketplaces have an advantage in achieving this due to providing better expected matches, one can reasonably expect that the descending search order would still be optimal.

Relying on the aforementioned assumptions, our paper provides a tractable framework 
for an analysis of general market structures while taking search frictions into account. We concentrate on the unique "robust" equilibrium, i.e. an equilibrium which exists for all industry structures. The search order in this equilibrium is determined by three forces working to make larger marketplaces more attractive to consumers: lower prices caused by a higher elasticity of demand and a larger number of competitors, and larger variety. Our entry results accommodate both central (see Dudey (1990)) and core-periphery (see Fischer and Harrington (1996)) structures, which naturally arise from the same framework for various parameter values. Our result, that the mall size is decreasing in search frictions (except for the lowest values of $s$ ), offers an explanation to why there is a larger concentration of stores in on-line marketplaces than in their off-line counterparts. The framework developed in this paper can be used in the analysis of various questions, including platform pricing, sequential entry, and the development of socially optimal search technology. 


\section{Appendix: Proofs}

Proof of Proposition 2. We construct our proof in several steps. In step 1, we derive profit-maximizing prices given the behaviour of consumers and obtain an expression similar to (7), while not yet imposing that the assumed equilibrium beliefs about prices are correct $^{12}$. In step 2, we prove that those prices must belong to a compact convex set. In step 3, we apply the Brouwer fixed point theorem to ensure existence of a fixed point. In step 4, we show that prices are indeed monotone, thus the monotonicity of $z_{k}$ 's is guaranteed. Finally, in step 5 we refine the price range by imposing the equilibrium condition $p_{k}^{e}=p_{k}$.

Step 1: optimal price By differentiation of (6) with respect to $\hat{p}_{k}$ we obtain

$$
\begin{aligned}
\frac{\partial \pi_{k}}{\partial \hat{p}_{k}}= & D_{k}\left(\hat{p}_{k}\right)-\hat{p}_{k} h_{k}\left[\left(\min \left\{z_{k}+p_{k}, 1\right\}\right)^{N_{k}-1}+\right. \\
& \left.\int_{z_{k}+\hat{p}_{k}}^{1}\left(N_{k}-1\right)\left(\min \left\{u-\hat{p}_{k}+p_{k}, 1\right\}\right)^{N_{k}-2} \mathbb{I}_{u-\hat{p}_{k}+p_{k}<1} d u\right]=0
\end{aligned}
$$

where $\mathbb{I}_{u-\hat{p}_{k}+p_{k}<1}$ is an indicator function, which takes value of 1 if $u-\hat{p}_{k}+p_{k}<1$ and zero otherwise. In equilibrium, $\hat{p}_{k}=p_{k}$, and thus

$$
\begin{array}{r}
D_{k}\left(p_{k}\right)-p_{k} h_{k}\left(\left(\min \left\{z_{k}+p_{k}, 1\right\}\right)^{N_{k}-1}+1-\left(\min \left\{z_{k}+p_{k}, 1\right\}\right)^{N_{k}-1}\right)= \\
r_{k}+h_{k}\left(\frac{1-\left(z_{k}+p_{k}\right)^{N_{k}}}{N_{k}}\right)-p_{k} h_{k}=0,
\end{array}
$$

which gives

$$
p_{k}=\frac{1-\left(z_{k}+p_{k}\right)^{N_{k}}}{N_{k}}+\frac{r_{k}}{h_{k}} .
$$

Step 2: coarse price range. Now we prove that prices belong to a compact and convex set. Firstly, since $r_{k}(p) / h_{k}(p)>0$, we immediately get that $p_{k} \geq \frac{1-a_{k}^{N_{k}}}{N_{k}}$. Next,

\footnotetext{
${ }^{12} \mathrm{We}$ only derive the first order condition here. Once the symmetry of prices in the same cohort and consistency of beliefs are imposed, it can be shown that the profit function is concave for $\tilde{p}<p_{k}$ and log-concave for $\tilde{p}>p_{k}$ and hence it is log-concave. The first order condition then delivers the global maximum of the profit function. This proof is available upon request.
} 
rewrite (11) as

$$
p_{k}=\frac{1}{2}\left[\frac{1-\left(z_{k}+p_{k}\right)^{N_{k}}}{N_{k}}\right]+\frac{p_{k}}{2}+\frac{1}{2} \frac{r_{k}}{h_{k}} .
$$

Now recall that

$$
\begin{aligned}
& r_{k}=\sum_{i=k}^{K} \int_{z_{i+1}}^{z_{i}}[\left.\prod_{j \leq i, j \neq k}\left(u+p_{j}\right)^{N_{j} M_{j}}\right]\left(u+p_{k}\right)^{N_{k} M_{k}-1} d u< \\
& \sum_{i=k}^{K}\left(z_{i}-z_{i+1}\right) \prod_{j \leq i, j \neq k}\left(z_{i}+p_{j}\right)^{N_{j} M_{j}}\left(z_{i}+p_{k}\right)^{N_{k} M_{k}-1} \leq \\
& \sum_{i=k}^{K}\left(z_{i}-z_{i+1}\right) \prod_{j \leq k-1}\left(z_{k}+p_{j}\right)^{N_{j} M_{j}}\left(z_{k}+p_{k}\right)^{N_{k} M_{k}-1} \leq \\
& z_{k} \prod_{j \leq k-1}\left(z_{k}+p_{j}\right)^{N_{j} M_{j}}\left(z_{k}+p_{k}\right)^{N_{k} M_{k}-1},
\end{aligned}
$$

where the first inequality comes from the fact that the integrand is an increasing function, the second inequality is obtained from the fact that all terms do not exceed one and $z_{k}$ is a monotonically decreasing sequence due to consumers' expectations, and the last one comes from expanding the sum and using $z_{K}=0$. Then,

$$
\begin{aligned}
& \frac{r_{k}}{h_{k}} \leq \frac{z_{k} \prod_{j \leq k-1}\left(z_{k}+p_{j}\right)^{N_{j} M_{j}}\left(z_{k}+p_{k}\right)^{N_{k} M_{k}-1}}{\left[\prod_{j \leq k-1}\left(z_{k}+p_{j}\right)^{N j M_{j}}\right]\left[\frac{1}{M_{k}} \sum_{j=1}^{M_{k}}\left(z_{k}+p_{k}\right)^{(j-1) N_{k}}\right]}= \\
& =z_{k} \frac{M_{k}\left(z_{k}+p_{k}\right)^{N_{k} M_{k}-1}\left[1-\left(z_{k}+p_{k}\right)^{N_{k}}\right]}{1-\left(z_{k}+p_{k}\right)^{N_{k} M_{k}}} \leq \\
& z_{k} \frac{1-\left(z_{k}+p_{k}\right)^{N_{k}}}{N_{k}\left[1-\left(z_{k}+p_{k}\right)\right]} \leq z_{k}
\end{aligned}
$$

Thus,

$$
p_{k} \leq \frac{1}{2}\left[\frac{1-\left(z_{k}+p_{k}\right)^{N_{k}}}{N_{k}}\right]+\frac{z_{k}+p_{k}}{2} .
$$

The right-hand side is an increasing function of $\left(z_{k}+p_{k}\right)$ and achieves its maximum of $1 / 2$ when $z_{k}+p_{k}=1$. 
Step 3: the fixed point. Using the result from the previous step, we know that prices are bounded by $\left[\frac{1-a_{k}^{N_{k}}}{N_{k}}, \frac{1}{2}\right] \subseteq\left[0, \frac{1}{2}\right]$. Thus, the system of equations (7) defines a continuous (as $r_{k}$ and $h_{k}$ are continuous and $h_{k}>0$ ) bounded function mapping a compact convex set $\left[0, \frac{1}{2}\right]^{K}$ onto itself, which, by Brouwer's theorem, has a fixed point.

Step 4: monotonicity of prices. Note that for the search order described in Proposition 1 and any price vector $p$ it must be the case that $h_{k+1} \leq h_{k}$, as $h_{k}$ is the probability that the consumer reaches cohort $k$ in her search. Write the price difference as

$$
\begin{aligned}
p_{k+1}-p_{k}=\frac{1-\left(z_{k+1}+p_{k+1}\right)^{N_{k+1}}}{N_{k+1}}-\frac{1-\left(z_{k}+p_{k}\right)^{N_{k}}}{N_{k}}+\frac{r_{k+1}}{h_{k+1}}-\frac{r_{k}}{h_{k}} \\
\quad>\frac{1-\left(z_{k+1}+p_{k+1}\right)^{N_{k+1}}}{N_{k+1}}-\frac{1-\left(z_{k}+p_{k}\right)^{N_{k}}}{N_{k}}+\frac{r_{k+1}-r_{k}}{h_{k}} .
\end{aligned}
$$

Now, we can rewrite

$$
\begin{gathered}
r_{k+1}-r_{k}=\sum_{i=k+1}^{K} \int_{z_{i+1}}^{z_{i}}\left[\prod_{j \leq i, j \neq k+1}\left(u+p_{j}\right)^{N_{j} M_{j}}\right]\left(u+p_{k+1}\right)^{N_{k+1} M_{k+1}-1} d u \\
-\sum_{i=k}^{K} \int_{z_{i+1}}^{z_{i}}\left[\prod_{j \leq i, j \neq k}\left(u+p_{j}\right)^{N_{j} M_{j}}\right]\left(u+p_{k}\right)^{N_{k} M_{k}-1} d u \\
=\left(p_{k}-p_{k+1}\right) \underbrace{\sum_{i=k+1}^{K} \int_{z_{i+1}}^{z_{i}}\left[\prod_{j \leq i, j \neq k, k+1}\left(u+p_{j}\right)^{\left.N_{j} M_{j}\right]}\right]\left(u+p_{k}\right)^{N_{k} M_{k}-1}\left(u+p_{k+1}\right)^{N_{k+1} M_{k+1}-1} d u}_{A} \\
-\underbrace{\int_{z_{k+1}}^{z_{k}}\left[\prod_{j \leq k-1}\left(u+p_{j}\right)^{N_{j} M_{j}}\right]\left(u+p_{k}\right)^{N_{k} M_{k}-1} d u}_{B} .
\end{gathered}
$$

Then, 


$$
\begin{gathered}
\frac{B}{h_{k}}=-\frac{\int_{z_{k+1}}^{z_{k}}\left[\prod_{j \leq k-1}\left(u+p_{j}\right)^{N_{j} M_{j}}\right]\left(u+p_{k}\right)^{N_{k} M_{k}-1} d u}{\left[\prod_{j=1}^{k-1}\left(z_{k}+p_{j}\right)^{N j M_{j}}\right]\left[\frac{1}{M_{k}} \sum_{j=1}^{M_{k}}\left(z_{k}+p_{k}\right)^{(j-1) N_{k}}\right]} \\
\geq-\frac{\int_{z_{k+1}}^{z_{k}}\left[\prod_{j \leq k-1}\left(z_{k}+p_{j}\right)^{N_{j} M_{j}}\right]\left(z_{k}+p_{k}\right)^{N_{k}\left(M_{k}-1\right)}\left(u+p_{k}\right)^{N_{k}-1} d u}{\left[\prod_{j=1}^{k-1}\left(z_{k}+p_{j}\right)^{N j M_{j}}\right]\left[\frac{1}{M_{k}} \sum_{j=1}^{M_{k}}\left(z_{k}+p_{k}\right)^{(j-1) N_{k}}\right]} \\
=-\frac{\left(z_{k}+p_{k}\right)^{N_{k}\left(M_{k}-1\right)}}{\frac{1}{M_{k}} \sum_{j=1}^{M_{k}}\left(z_{k}+p_{k}\right)^{(j-1) N_{k}}} \int_{z_{k+1}}^{z_{k}}\left(u+p_{k}\right)^{N_{k}-1} d u \\
\geq-\int_{z_{k+1}}^{z_{k}}\left(u+p_{k}\right)^{N_{k}-1} d u=\frac{\left(z_{k+1}+p_{k}\right)^{N_{k}}}{N_{k}}-\frac{\left(z_{k}+p_{k}\right)^{N_{k}}}{N_{k}} .
\end{gathered}
$$

By plugging this back into (13), we obtain

$$
\begin{gathered}
p_{k+1}-p_{k}>\frac{1-\left(z_{k+1}+p_{k+1}\right)^{N_{k+1}}}{N_{k+1}}-\frac{1-\left(z_{k}+p_{k}\right)^{N_{k}}}{N_{k}} \\
-\frac{\left(z_{k}+p_{k}\right)^{N_{k}}}{N_{k}}+\frac{\left(z_{k+1}+p_{k}\right)^{N_{k}}}{N_{k}}+\left(p_{k}-p_{k+1}\right) \frac{A}{h_{k}} \\
=\frac{1-\left(z_{k+1}+p_{k+1}\right)^{N_{k+1}}}{N_{k+1}}-\frac{1-\left(z_{k+1}+p_{k}\right)^{N_{k}}}{N_{k}}+\left(p_{k}-p_{k+1}\right) \frac{A}{h_{k}} .
\end{gathered}
$$

Now, as $\frac{1-\left(z_{k+1}+p_{k+1}\right)^{N_{k+1}}}{N_{k+1}}$ is a decreasing function of $N_{k+1}{ }^{13}$, and $N_{k}>N_{k+1}$, we get that

$$
\begin{aligned}
p_{k+1}-p_{k}>\frac{1-\left(z_{k+1}+p_{k+1}\right)^{N_{k}}}{N_{k}}- & \frac{1-\left(z_{k+1}+p_{k}\right)^{N_{k}}}{N_{k}}+\left(p_{k}-p_{k+1}\right) \frac{A}{h_{k}} \\
& =\sum_{j=0}^{N_{k}}\left(\begin{array}{c}
N_{k} \\
j
\end{array}\right) z_{k+1}^{j}\left[p_{k}^{N_{k}-j}-p_{k+1}^{N_{k}-j}\right]+\left(p_{k}-p_{k+1}\right) \frac{A}{h_{k}},
\end{aligned}
$$

which can hold only if $p_{k+1}>p_{k}$. Thus, prices must be monotone. Finally, by plugging $p_{k}^{e}=p_{k}$ into (11) we obtain (7).

Step 5: refined price range. Here, we refine the upper bound of the price sequence. Using the fact that in equilibrium $z_{k}=a_{k}-p_{k}$ and the upper bound on $r_{k}$ derived in step 2 , we get

\footnotetext{
${ }^{13}$ Note, that this expression can be written as $\frac{1-a^{N}}{N}$, which is decreasing as long as $a^{N} \ln a^{N}>1-a^{N}$, which always holds as $\ln \left(1 / a^{N}\right)<1 / a^{N}-1$.
} 


$$
r_{k}<\left(a_{k}-p_{k}\right)\left[\prod_{j=1}^{k-1}\left(a_{k}-p_{k}+p_{j}\right)^{N_{j} M_{j}}\right] a_{k}^{N_{k} M_{k}-1} .
$$

By cancelling the product terms we obtain

$$
\frac{r_{k}(p)}{h_{k}(p)} \leq \frac{\left(a_{k}-p_{k}\right) a_{k}^{N_{k} M_{k}-1}}{\frac{1}{M_{k}} \sum_{j=1}^{M_{k}} a_{k}^{(j-1) N_{k}}}=\left(a_{k}-p_{k}\right) \frac{M_{k} a_{k}^{N_{k} M_{k}-1}\left(1-a_{k}^{N_{k}}\right)}{1-a_{k}^{N_{k} M_{k}}}
$$

Now, as $\frac{x a^{x-1}}{1-a^{x}}$ is a decreasing function of $x$ for $a<1$, the right hand side of the expression above attains its maximum at $N_{k} M_{k}=1$. Thus, we obtain

$$
\frac{r_{k}(p)}{h_{k}(p)} \leq\left(a_{k}-p_{k}\right) \frac{1-a_{k}^{N_{k}}}{N_{k}\left(1-a_{k}\right)}
$$

Now, we get that

$$
p_{k}=\frac{1-a_{k}^{N_{k}}}{N_{k}}+\frac{r_{k}}{h_{k}} \leq \frac{1-a_{k}^{N_{k}}}{N_{k}} \frac{1-p_{k}}{1-a_{k}},
$$

which gives

$$
p_{k} \leq \frac{1-a_{k}^{N_{k}}}{N_{k}\left(1-a_{k}\right)+1-a_{k}^{N_{k}}},
$$

which we use as the new upper bound. Note that the right hand side attains its maximum of $1 / 2$ for $N_{k}=1$.

Proof of Proposition 3. Consider a market configuration with one large mall of size $N$, and a stand-alone store. Suppose that there is an equilibrium in this market such that consumers start their search from the stand-alone store. Recall that in this case we define the reservation values $a_{1}$ and $a_{2}$ as

$$
\int_{a_{1}}^{1}\left(u-a_{1}\right) d u=s, \quad \int_{a_{2}}^{1} N\left(u-a_{2}\right) u^{N-1} d u=s .
$$

Note that as the first order conditions in this case are still determined by (7), from Theorem 2 it follows that $p_{1}>1-a_{1}>0($ as $s>0)$ and $p_{2} \leq \frac{1-a_{2}^{N}}{N\left(1-a_{2}\right)+1-a_{2}^{N}}$, which implies $p_{2}$ approaches zero as $N$ approaches infinity. At the same time, for any $N, a_{2}>a_{1}$. Therefore, for large enough $N$ the expected surplus from sampling the mall is larger than 
that from sampling the stand-alone store, $a_{2}-p_{2}>a_{1}-p_{1}$. Hence, starting the search from the stand-alone store is irrational.

Proof of Proposition 4. We first prove that $\pi_{k}=p_{k}^{2} \cdot h_{k}$. This is easily shown by plugging the value of $r_{k}$ from the F.O.C. (7) into the expression for profit:

$$
\pi_{k}=p_{k}\left[\frac{1-a_{k}^{N_{k}}}{N_{k}} h_{k}+r_{k}\right]=p_{k}\left[\frac{1-a_{k}^{N_{k}}}{N_{k}} h_{k}+p_{k} h_{k}-\frac{1-a_{k}^{N_{k}}}{N_{k}} h_{k}\right]=p_{k}^{2} h_{k} .
$$

Next write down the profit of a firm in cohort $k$ as $\pi_{k}\left(p_{k}, p_{-k}\right)=p_{k} D_{k}\left(p_{k}, p_{-k}\right)$ where $p_{-k}$ are equilibrium prices played by other firms, including those in the same cohort and the same mall. Then, as $p_{k}$ is the optimal price, we obtain

$$
\pi_{k}\left(p_{k}, p_{-k}\right)=p_{k} D_{k}\left(p_{k}, p_{-k}\right)>p_{k+1} D_{k}\left(p_{k+1}, p_{-k}\right) .
$$

Now, due to the descending search order, we get $D_{k}\left(p_{k+1}, p_{-k}\right)>D_{k+1}\left(p_{k+1}, p_{-k}\right)$. Hence,

$$
\begin{array}{r}
\pi_{k}\left(p_{k}, p_{-k}\right)=p_{k} D_{k}\left(p_{k}, p_{-k}\right)>p_{k+1} D_{k}\left(p_{k+1}, p_{-k}\right)>p_{k+1} D_{k+1}\left(p_{k+1}, p_{-k}\right) \\
>p_{k+1} D_{k+1}\left(p_{k}, p_{-k}\right),
\end{array}
$$

where the last inequality follows form $p_{k}<p_{k+1}$ and the fact that demand in cohort $k+1$ is increasing in prices of firms in cohort $k$. Finally, one can easily spot that the right hand side of (15) is just the profit of a firm in cohort $k+1$, which charges the equilibrium price $p_{k+1}$, which completes the proof.

\section{Proof of Lemma 5.}

Uniqueness. For our special case of one mall, the first order conditions for a firm inside and outside the mall take the following form:

$$
\begin{aligned}
G_{1}\left(p_{1}, p_{2}\right) & \equiv p_{1}-\frac{1}{N}+\frac{\left(a-p_{2}+p_{1}\right)^{N}}{N}-\int_{0}^{a-p_{2}}\left(u+p_{1}\right)^{N-1}\left(u+p_{2}\right)^{M} d u=0, \\
G_{2}\left(p_{1}, p_{2}\right) & \equiv\left(p_{2}-1+a\right) \cdot \underbrace{\frac{1+\ldots+a^{M-1}}{M}}_{\equiv g(a)} \cdot\left(a-p_{2}+p_{1}\right)^{N} \\
& -\int_{0}^{a-p_{2}}\left(u+p_{1}\right)^{N}\left(u+p_{2}\right)^{M-1} d u=0 .
\end{aligned}
$$


Since $G$ 's are continuously differentiable, the implicit function theorem implies that each $G_{i}\left(p_{1}, p_{2}\right)=0$ defines an implicit relationship

$$
\eta_{i}\left(p_{2}\right):\left[1-a, \frac{1}{2}\right] \rightarrow\left[\frac{1}{N}-\frac{a^{N}}{N}, \frac{1}{2}\right]
$$

between $p_{1}$ and $p_{2}$. We will informally refer to $\eta_{1}\left(p_{2}\right)$ and $\eta_{2}\left(p_{2}\right)$ as the best response of the firm in the mall and the (indirect) best response of a stand-alone store, respectively.

By implicit function theorem,

$$
\frac{\partial \eta_{1}}{\partial p_{2}}=-\frac{\frac{\partial G_{1}}{\partial p_{2}}}{\frac{\partial G_{1}}{\partial p_{1}}}, \quad \frac{\partial \eta_{2}}{\partial p_{2}}=-\frac{\frac{\partial G_{2}}{\partial p_{2}}}{\frac{\partial G_{2}}{\partial p_{1}}} .
$$

We have

$$
\begin{aligned}
& \frac{\partial G_{1}}{\partial p_{2}}=\left(a-p_{2}+p_{1}\right)^{N-1}\left(a^{M}-1\right)-\int_{0}^{a-p_{2}}\left(u+p_{1}\right)^{N-1} M \cdot\left(u+p_{2}\right)^{M-1} d u<0, \\
& \frac{\partial G_{1}}{\partial p_{1}}=1+\left(a-p_{2}+p_{1}\right)^{N-1}-\int_{0}^{a-p_{2}}(N-1)\left(u+p_{1}\right)^{N-2} \cdot\left(u+p_{2}\right)^{M} d u>1,
\end{aligned}
$$

since

$$
\begin{gathered}
-\int_{0}^{a-p_{2}}(N-1)\left(u+p_{1}\right)^{N-2} \cdot\left(u+p_{2}\right)^{M} d u>-a^{M} \int_{0}^{a-p_{2}}(N-1)\left(u+p_{1}\right)^{N-2} d u \\
=-a^{M}\left[\left(a-p_{2}+p_{1}\right)^{N-1}-p_{1}^{N-1}\right]>-\left(a-p_{2}+p_{1}\right)^{N-1} .
\end{gathered}
$$

From this, $\frac{\partial \eta_{1}}{\partial p_{2}}>0$. Furthermore,

$$
\frac{\partial \eta_{1}}{\partial p_{2}}-1=\frac{-\frac{\partial G_{1}}{\partial p_{2}}-\frac{\partial G_{1}}{\partial p_{1}}}{\frac{\partial G_{1}}{\partial p_{1}}}<0
$$

since

$$
\begin{gathered}
-\frac{\partial G_{1}}{\partial p_{2}}-\frac{\partial G_{1}}{\partial p_{1}}=-a^{M}\left(a-p_{2}+p_{1}\right)^{N-1}-1 \\
+\int_{0}^{a-p_{2}}(N-1)\left(u+p_{1}\right)^{N-2}\left(u+p_{2}\right)^{M} d u+\int_{0}^{a-p_{2}}\left(u+p_{1}\right)^{N-1} \cdot M\left(u+p_{2}\right)^{M-1} d u \\
<-a^{M}\left(a-p_{2}+p_{1}\right)^{N-1}-1+a^{M} \cdot\left[\left(a-p_{2}+p_{1}\right)^{N-1}-p_{1}^{N-1}\right]+\left(a-p_{2}+p_{1}\right)^{N-1} \cdot\left[a^{M}-p_{2}^{M}\right]<0 .
\end{gathered}
$$

Hence, we conclude that $\frac{\partial \eta_{1}}{\partial p_{2}} \in(0,1)$. 
Similarly, we show below that

$$
\frac{\partial \eta_{2}}{\partial p_{2}}-1=\frac{-\frac{\partial G_{2}}{\partial p_{2}}-\frac{\partial G_{2}}{\partial p_{1}}}{\frac{\partial G_{2}}{\partial p_{1}}}>0
$$

We have

$\frac{\partial G_{2}}{\partial p_{1}}=N\left(a-p_{2}+p_{1}\right)^{N-1} \cdot g(a)\left(p_{2}-1+a\right)-\int_{0}^{a-p_{2}} N\left(u+p_{1}\right)^{N-1}\left(u+p_{2}\right)^{M-1} d u<0$,

since we know from the F.O.C. of the stand-alone firm that

$$
\begin{gathered}
N\left(a-p_{2}+p_{1}\right)^{N-1} \cdot g(a)\left(p_{2}-1+a\right)=\frac{N}{a-p_{2}+p_{1}} \int_{0}^{a-p_{2}}\left(u+p_{1}\right)^{N}\left(u+p_{2}\right)^{M-1} d u \\
<\int_{0}^{a-p_{2}} N\left(u+p_{1}\right)^{N-1}\left(u+p_{2}\right)^{M-1} d u .
\end{gathered}
$$

Also,

$$
\begin{gathered}
-\frac{\partial G_{2}}{\partial p_{2}}-\frac{\partial G_{2}}{\partial p_{1}}=-g(a) \cdot\left(a-p_{2}+p_{1}\right)^{N}-a^{M-1}\left(a-p_{2}+p_{1}\right)^{N} \\
+\int_{0}^{a-p_{2}} N\left(u+p_{1}\right)^{N-1}\left(u+p_{2}\right)^{M-1} d u+\int_{0}^{a-p_{2}}\left(u+p_{1}\right)^{N} \cdot(M-1)\left(u+p_{2}\right)^{M-2} d u<0
\end{gathered}
$$

using the same upper bound as we did when calculating $-\frac{\partial G_{1}}{\partial p_{2}}-\frac{\partial G_{1}}{\partial p_{1}}$ and the fact that $g(a) \geq a^{M-1} \geq a^{M}$.

To summarize, $\frac{\partial \eta_{1}}{\partial p_{2}} \in(0,1)$ and $\frac{\partial \eta_{2}}{\partial p_{2}}>1$. Since we know from Proposition 2 that there exists a solution with $p_{1}<p_{2}$, this solution (the intersection of the best responses) must be unique.

Prices. By the implicit function theorem,

$$
\frac{\partial \eta_{1}}{\partial a}=-\frac{\frac{\partial G_{1}}{\partial a}}{\frac{\partial G_{1}}{\partial p_{1}}}<0
$$

since $\frac{\partial G_{1}}{\partial a}=\left(a-p_{2}+p_{1}\right)^{N-1}\left(1-a^{M}\right)>0$ and we proved previously that $\frac{\partial G_{1}}{\partial p_{1}}>0$.

Similarly,

$$
\frac{\partial \eta_{2}}{\partial a}=-\frac{\frac{\partial G_{2}}{\partial a}}{\frac{\partial G_{2}}{\partial p_{1}}}>0
$$

since

$$
\frac{\partial G_{2}}{\partial a}=g(a)\left(a-p_{2}+p_{1}\right)^{N}+g^{\prime}(a)\left(p_{2}-1+a\right) \cdot\left(a-p_{2}+p_{1}\right)^{N}
$$




$$
+N\left(a-p_{2}+p_{1}\right)^{N-1} \cdot g(a)-a^{M-1}\left(a-p_{2}+p_{1}\right)^{N}>0
$$

because $g(a) \geq a^{M-1}$ and we previously proved that $\frac{\partial G_{2}}{\partial p_{1}}<0$.

Consequently, as $s$ increases ( $a$ goes down), the best response of the mall shifts up (to the left), while the best response of the stand-alone store shifts down (to the right). This results in higher equilibrium prices. Lemma 5 guarantees that after the change in $a$ there will exist a unique intersection of the best responses with $p_{1}<p_{2}$. The effect of a rise in the search cost from 0.05 to 0.09 when $N=3$ and $M=2$ is illustrated in figure 4 .

Figure 4: Effect of a rise in search costs.

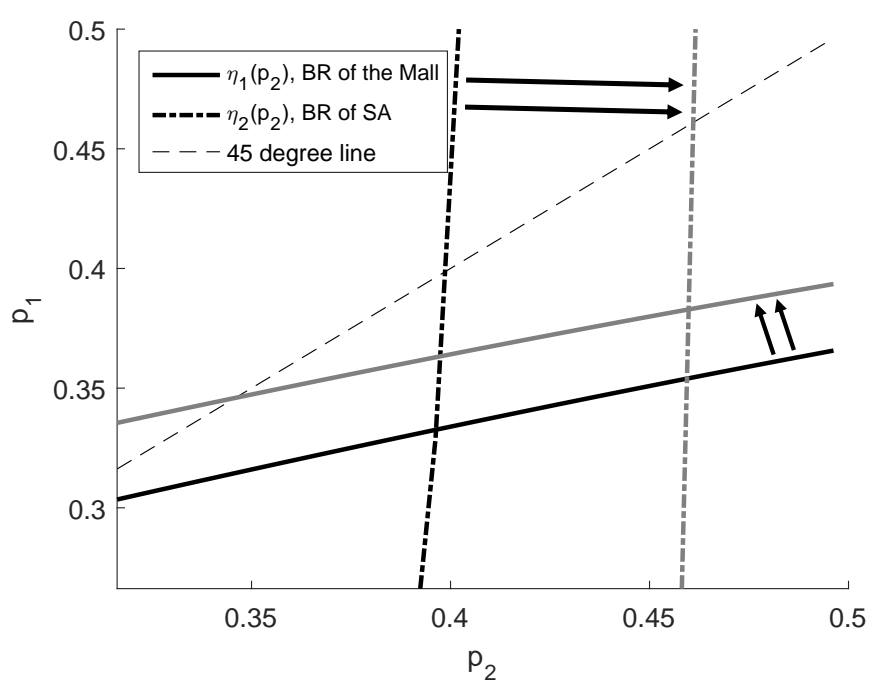

Profit in the mall. We prove that the profit of firms in the mall is increasing in $s$. To see this, recall that from $(8) \pi_{1}=p_{1}^{2}$ since we normalized $h_{1}=1$. Then, $\pi_{1}$ is increasing in $s$ because $p_{1}$ is.

Profit of a stand-alone firm for $M=1$. We prove that the profit of stand-alone firms is not monotone. To simplify our task we let $M=1$ and deal with only one stand-alone store in the market. From (8),

$$
\pi_{2}\left(p_{1}, p_{2}\right)=p_{2}^{2}\left(a-p_{2}+p_{1}\right)^{N} .
$$


Next, we change variables to $p_{2}=p_{2}$ and $a-p_{2}+p_{1}=x$. The F.O.C.s now become ${ }^{14}$

$$
\begin{aligned}
& 0=H_{1}\left(x, p_{2}\right) \equiv x-a+p_{2}-\frac{1}{N}+(1-a) \frac{x^{N}}{N}+\frac{p_{2}\left(x-a+p_{2}\right)^{N}}{N}+\frac{x^{N+1}}{N(N+1)}-\frac{\left(x-a+p_{2}\right)^{N+1}}{N(N+1)} \\
& 0=H_{2}\left(x, p_{2}\right) \equiv\left(p_{2}-1+a\right) x^{N}-\frac{x^{N+1}}{N+1}+\frac{\left(x-a+p_{2}\right)^{N+1}}{N+1}
\end{aligned}
$$

The implicit function theorem gives us the following expression:

$$
\left[\begin{array}{cc}
\frac{\partial H_{1}}{\partial x} & \frac{\partial H_{1}}{\partial p_{2}} \\
\frac{\partial H_{2}}{\partial x} & \frac{\partial H_{2}}{\partial p_{2}}
\end{array}\right]\left[\begin{array}{c}
\frac{\partial x}{\partial a} \\
\frac{\partial p_{2}}{\partial a}
\end{array}\right]=-\left[\begin{array}{c}
\frac{\partial H_{1}}{\partial a} \\
\frac{\partial H_{2}}{\partial a}
\end{array}\right]
$$

We solve this system for $\frac{\partial x}{\partial a}$ and $\frac{\partial p_{2}}{\partial a}$ using the Kramer rule:

$$
\frac{\partial x}{\partial a}=-\frac{\frac{\partial H_{1}}{\partial a} \frac{\partial H_{2}}{\partial p_{2}}-\frac{\partial H_{1}}{\partial p_{2}} \frac{\partial H_{2}}{\partial a}}{\frac{\partial H_{1}}{\partial x} \frac{\partial H_{2}}{\partial p_{2}}-\frac{\partial H_{2}}{\partial x} \frac{\partial H_{1}}{\partial p_{2}}}, \quad \frac{\partial p_{2}}{\partial a}=-\frac{\frac{\partial H_{1}}{\partial x} \frac{\partial H_{2}}{\partial a}-\frac{\partial H_{1}}{\partial a} \frac{\partial H_{2}}{\partial x}}{\frac{\partial H_{1}}{\partial x} \frac{\partial H_{2}}{\partial p_{2}}-\frac{\partial H_{2}}{\partial x} \frac{\partial H_{1}}{\partial p_{2}}} .
$$

Now, for the derivative of the profit we have

$$
\begin{gathered}
\frac{\partial \pi_{2}}{\partial a}=2 p_{2} x^{N} \cdot \frac{\partial p_{2}}{\partial a}+N x^{N-1} \cdot \frac{\partial x}{\partial a} \cdot p_{2}^{2} \\
=\frac{2 p_{2} x^{N}\left[-\frac{\partial H_{1}}{\partial x} \frac{\partial H_{2}}{\partial a}+\frac{\partial H_{1}}{\partial a} \frac{\partial H_{2}}{\partial x}\right]+N x^{N-1} \cdot p_{2}^{2}\left[-\frac{\partial H_{1}}{\partial a} \frac{\partial H_{2}}{\partial p_{2}}+\frac{\partial H_{1}}{\partial p_{2}} \frac{\partial H_{2}}{\partial a}\right]}{\frac{\partial H_{1}}{\partial x} \frac{\partial H_{2}}{\partial p_{2}}-\frac{\partial H_{2}}{\partial x} \frac{\partial H_{1}}{\partial p_{2}}} .
\end{gathered}
$$

After calculating the partial derivatives of $H_{1}$ and $H_{2}$, we get that $\frac{\partial \pi_{2}}{\partial a}=\frac{f(a)}{g(a)}$ where

$$
f(a) \equiv-x^{N-1} p_{2}^{2}\left[x^{N}-\left(x-a+p_{2}\right)^{N}\right]^{2}+2(1-a) N x^{2 N-1} p_{2}\left[1+p_{2}\left(x-a+p_{2}\right)^{N-1}\right]
$$

and

$$
\begin{aligned}
& g(a)=\left[-N x^{N-1}\left(p_{2}-1+a\right)+2 x^{N}\right]\left[1+p_{2}\left(x-a+p_{2}\right)^{N-1}\right] \\
& +\left[x^{N}+\left(x-a+p_{2}\right)^{N}\right]\left[(1-a) x^{N-1}+\frac{x^{N}}{N}-\frac{\left(x-a+p_{2}\right)^{N}}{N}\right] .
\end{aligned}
$$

\footnotetext{
${ }^{14}$ When $M=1$, we can evaluate both integrals (returning demands), which simplifies analysis just enough so we can say things about $\frac{\partial \pi_{2}}{\partial a}$. The integral from the F.O.C. for the mall $\int_{0}^{a-p_{2}}\left(u+x-a+p_{2}\right)^{N-1}\left(u+p_{2}\right) d u$ is taken by parts.
} 
Consider the numerator first. As $x^{N}>\left(x-a+p_{2}\right)^{N}$ we can rewrite equation $f(a)=0$ in the following form

$$
x^{-N / 2}\left(x^{N}-\left(x-a+p_{2}\right)^{N}\right)=\sqrt{\frac{2(1-a) N}{p_{2}}\left[1+p_{2}\left(x-a+p_{2}\right)^{N-1}\right]} .
$$

Our goal is to show that equation (16) has a unique solution in $a$. First, we show that the left hand side is increasing in $a$. Note, that

$$
\begin{gathered}
\frac{\partial}{\partial a}\left[x^{-N / 2}\left(x^{N}-\left(x-a+p_{2}\right)^{N}\right)\right]=-\frac{N}{2} x^{-N / 2-1}\left[x^{N}-\left(x-a+p_{2}\right)^{N}\right] \frac{\partial x}{\partial a}+ \\
x^{-N / 2}\left[N x^{N-1} \frac{\partial x}{\partial a}-N\left(x-a+p_{2}\right)^{N-1}\left(\frac{\partial x}{\partial a}-1+\frac{\partial p_{2}}{\partial a}\right)\right]> \\
{\left[-\frac{N}{2} x^{-N / 2-1} x^{N}+\frac{N}{2} x^{-N / 2-1}\left(x-a+p_{2}\right)^{N}+N x^{-N / 2} x^{N-1}\right] \frac{\partial x}{\partial a}=} \\
{\left[\frac{N}{2} x^{-N / 2} x^{N-1}+\frac{N}{2} x^{-N / 2-1}\left(x-a+p_{2}\right)^{N}\right] \frac{\partial x}{\partial a}>0}
\end{gathered}
$$

The first inequality comes from the fact that $\frac{\partial x}{\partial a}-1+\frac{\partial p_{2}}{\partial a}=\frac{\partial p_{1}}{\partial a}<0$, and the last inequality comes from

$$
\frac{\partial x}{\partial a}=\frac{1}{N g(a)}\left[x^{2 N}-\left(x-a+p_{2}\right)^{2 N}+2 x^{N}\left(1+p_{2} p_{1}^{N-1}\right)\right]>0
$$

Now we show that the right-hand side of (16) is decreasing in $a$. Note, that $p_{2}(x-$ $\left.a+p_{2}\right)^{N-1}=p_{2} p_{1}^{N-1}$ is a decreasing function of $a$. Thus, the sufficient condition for the right-hand side of (16) to be decreasing is that $\frac{1-a}{p_{2}}$ is a decreasing function. 


$$
\begin{aligned}
& \frac{\partial}{\partial a}\left(\frac{1-a}{p_{2}}\right)=-\frac{1}{p_{2}}-\frac{1-a}{p_{2}^{2}} \frac{\partial p_{2}}{\partial a}= \\
& \frac{1}{g(a)}\left\{\left[N x^{N-1}+\frac{1-a}{p_{2}} N x^{N-1}+\frac{2 x^{N}}{p_{2}}\right] \cdot\left[1+p_{2}\left(x-a+p_{2}\right)^{N-1}\right]\right. \\
& \left.+\left[x^{N}+\left(x-a+p_{2}\right)^{N}\right]\left[\frac{1-a}{p_{2}} x^{N-1}+\frac{x^{N}-(x-a+p 2)^{N}}{N p_{2}}\right]\right\}+ \\
& -\frac{1}{g(a)} \frac{1-a}{p_{2}}\left\{-N x^{N-1}\left[1+p_{2}\left(x-a+p_{2}\right)^{N-1}+\frac{x^{N}-\left(x-a+p_{2}\right)^{N}}{N}\right]+\right. \\
& \left.\quad \frac{1-a}{p_{2}} N x^{N-1}\left[1+p_{2}\left(x-a+p_{2}\right)^{N-1}\right]\right\}= \\
& \frac{1}{g(a)}\left\{\left[1+p_{2}\left(x-a+p_{2}\right)^{N-1}\right]\left[N x^{N-1}\left(1-\frac{(1-a)^{2}}{p_{2}^{2}}\right)-\frac{2 x^{N}}{p_{2}}\right]\right. \\
& \left.\quad-\frac{1}{N p_{2}}\left[x^{2 N}-\left(x-a+p_{2}\right)^{2 N}\right]-2 \frac{1-a}{p_{2}} x^{N-1}\left(x-a+p_{2}\right)^{N}\right\}
\end{aligned}
$$

Thus, the right-hand side of (16) is a decreasing function if

$$
N\left(1-\frac{(1-a)^{2}}{p_{2}^{2}}\right)-\frac{2 x}{p_{2}}<0
$$

Note, that the first order condition for the stand-alone firm rewritten in terms of $x$ is

$$
p_{2}=(1-a)+\frac{1}{N+1}\left[x-\frac{\left(x-a+p_{2}\right)^{N+1}}{x^{N}}\right]
$$

Thus,

$$
(1-a)^{2}=\left[p_{2}-\frac{x}{N+1}+\frac{\left(x-a+p_{2}\right)^{N+1}}{(N+1) x^{N}}\right]^{2}>\left[p_{2}-\frac{x}{N+1}\right]^{2}
$$

Therefore,

$$
\begin{aligned}
& N\left(1-\frac{(1-a)^{2}}{p_{2}^{2}}\right)-\frac{2 x}{p_{2}}=\frac{N}{p_{2}^{2}}\left[p_{2}^{2}-(1-a)^{2}\right]-\frac{2 x}{p_{2}}< \\
& \frac{N}{p_{2}^{2}}\left[\frac{2 x}{N+1} p_{2}-\frac{x^{2}}{(N+1)^{2}}\right]-\frac{2 x}{p_{2}}=\frac{2 x}{p_{2}}\left(\frac{N}{N+1}-1\right)-\frac{x^{2}}{(N+1)^{2}} \frac{N}{p_{2}^{2}}<0
\end{aligned}
$$

Thus, the right-hand side of (16) is decreasing in $a$, while the left-hand side is increasing in $a$. Therefore, equation $f(a)=0$ has at most one solution. To show that a solution 
exists we consider the value of $f(a)$ at the boundaries, i.e. when $a=\frac{1}{2}$ and $a=1^{15}$. We have

$$
\begin{gathered}
f(1 / 2)=\frac{1}{2} N x^{2 N-1}\left[1+\frac{x^{N-1}}{2}\right]>0, \\
f(1)=-p^{2}\left(1-p^{N}\right)^{2}<0 .
\end{gathered}
$$

To summarize, $f(a)$ is positive at $a=1 / 2$, equals to zero at some $a_{0} \in(1 / 2,1)$, and then becomes negative.

To show that $g(a)$ is positive we show that $2 x^{N}-N x^{N-1}\left(p_{2}-1+a\right)$ is positive. From the second F.O.C. we have

$$
p_{2}-1+a=\frac{1}{x^{N}}\left[\frac{x^{N+1}}{N+1}-\frac{\left(x-a+p_{2}\right)^{N+1}}{N+1}\right] .
$$

Then,

$$
2 x^{N}-N x^{N-1}\left(p_{2}-1+a\right)=\left(2-\frac{N}{N+1}\right) x^{N}+\frac{N}{N+1} \frac{\left(x-a+p_{2}\right)^{N}}{x}>0 .
$$

This completes our analysis of the behavior of $\pi_{2}$. We conclude that it increases for $a \in\left[1 / 2, a_{0}\right)$, reaches its maximum at $a_{0}$, and then decreases for $\left(a_{0}, 1\right]$. In terms of $s, \pi_{2}$ is increasing for $s \in\left[0, s_{0}\right)$ and decreasing for $s \in\left(s_{0}, 1 / 8\right]$.

\footnotetext{
${ }^{15}$ When $a=1 / 2$, the model converges to $p_{1}$ which solves $p_{1}=\frac{1}{N}-\frac{p_{1}^{N}}{N}, p_{2}=1 / 2, x=p_{1}$. When $a=1, x=1, p_{1}=p_{2}=p$ which solves $p=\frac{1}{N+1}-\frac{p^{N+1}}{N+1}$. This is the monopolistic competition price from Wolinsky model with zero search costs.
} 


\section{References}

Anderson, S. P. and Renault, R. (1999). Pricing, Product Diversity, and Search Costs: A Bertrand-Chamberlin-Diamond Model. RAND Journal of Economics, 30(4):719-735.

Arbatskaya, M. (2007). Ordered Search. RAND Journal of Economics, 38(1):119-126.

Armstrong, M. (2006). Competition in Two-Sided Markets. RAND Journal of Economics, $37(3): 668-691$.

Armstrong, M. (2017). Ordered consumer search. Journal of the European Economic Association, 15(5):989-1024.

Armstrong, M., Vickers, J., and Zhou, J. (2009). Prominence and Consumer Search. The RAND Journal of Economics, 40(2):209-233.

Armstrong, M. and Zhou, J. (2011). Paying for Prominence. The Economic Journal, 121(556):F368-F395.

Athey, S. and Ellison, G. (2011). Position Auctions with Consumer Search. The Quarterly Journal of Economics, 126(3):1213-1270.

Baye, M. R. and Morgan, J. (2001). Information Gatekeepers on the Internet and the Competitiveness of Homogeneous Product Markets. The American Economic Review, 91(3):454-474.

Dudey, M. (1990). Competition by Choice: The Effect of Consumer Search on Firm Location Decisions. The American Economic Review, 80(5):1092-1104.

Eaton, B. C. and Lipsey, R. G. (1979). Comparison Shopping and the Clustering of Homogeneous Firms. Journal of Regional Science, 19(4):421-435.

Fischer, J. H. and Harrington, J. E. (1996). Product Variety and Firm Agglomeration. The RAND Journal of Economics, 27(2):281-309. 
Fishman, A. and Lubensky, D. (2017). Search Prominence and Recall Costs. Kelley School of Business Research Paper No. 16-78.

Galeotti, A. and Moraga-González, J. L. (2009). Platform Intermediation in a Market for Differentiated Products. European Economic Review, 53(4):417-428.

Haan, M. A. and Moraga-González, J. L. (2011). Advertising for Attention in a Consumer Search Model. The Economic Journal, 121(552):552-579.

Janssen, M., Moraga-González, J. L., and Wildenbeest, M. R. (2005). Truly Costly Sequential Search and Oligopolistic Pricing. International Journal of Industrial Organization, 23(5-6):451-466.

Janssen, M. and Parakhonyak, A. (2014). Consumer Search Markets with Costly Revisits. Economic Theory, 55(2):481-514.

Moraga-González, J. L. and Petrikaitè, V. (2013). Search Costs, Demand-Side Economies, and the Incentives to Merge under Bertrand Competition. The RAND Journal of Economics, 44(3):391-424.

Moraga-González, J. L., Sándor, Z., and Wildenbeest, M. R. (2017). Prices and heterogeneous search costs. The RAND Journal of Economics, 48(1):125-146.

Non, M. (2010). Isolation or Joining a Mall? On the Location Choice of Competing Shops. Mimeo, University of Groningen.

Rhodes, A., Watanabe, M., and Zhou, J. (2017). Multiproduct intermediaries and optimal product range. Mimeo.

Ronayne, D. (2015). Price comparison websites. Mimeo.

Song, H. (2014). Electronic Platforms in a Consumer Search Model. Journal of Institutional and Theoretical Economics, 170(4):704-730. 
Stahl, D. O. (1989). Oligopolistic Pricing with Sequential Consumer Search. The American Economic Review, 79(4):700-712.

Stahl, K. (1982). Differentiated Products, Consumer Search, and Locational Oligopoly. The Journal of Industrial Economics, 31(1/2):97-113.

Wang, C. and Wright, J. (2016). Search Platforms: Showrooming and Price Parity Clauses. Mimeo.

Weitzman, M. (1979). Optimal Search for the Best Alternative. Econometrica, 47(3):64154.

Wilson, C. M. (2010). Ordered search and equilibrium obfuscation. International Journal of Industrial Organization, 28(5):496-506.

Wolinsky, A. (1983). Retail Trade Concentration due to Consumers' Imperfect Information. The Bell Journal of Economics, pages 275-282.

Wolinsky, A. (1986). True Monopolistic Competition as a Result of Imperfect Information. The Quarterly Journal of Economics, 101(3):493-511.

Zhou, J. (2011). Ordered Search in Differentiated Markets. International Journal of Industrial Organization, 29(2):253-262. 